\title{
mudanças na psicoterapia psicodinâmica de crianças na visão de pais e mães
}

\author{
Cambios en la psicoterapia psicodinámica de niños en la visión \\ de padres y madres \\ Changes in Child Psychodynamic Psychotherapy ficcording \\ to the Parents' Uiew
}

\author{
Vera Regina Rohnelt Ramires* \\ Cibele Carvalho* \\ Marina Bento Gastaud* \\ Universidade do Vale do Rio dos Sinos \\ Luiz Ronaldo Freitas de Oliveira** \\ Faculdades Meridionais, IMED \\ Lucia Belina Rech Godinho** \\ Centro Universitário La Salle, Brasil
}

Doi: http://dx.doi.org/10.12804/revistas.urosario.edu.co/apl/a.5458

\section{Resumo}

No campo da pesquisa em psicoterapia psicodinâmica das crianças, uma questão aberta é como avaliar sistematicamente as mudanças e quais se consideram fundamentais. Não se têm levado a cabo análises qualitativas acerca da visão de pais e mães. O objetivo deste estudo foi investigar a percepção de pais e mães sobre as possíveis mudanças em suas crianças durante suas psicoterapias. O estudo teve enfoque qualitativo, descritivo, longitudinal. Os participantes foram pais e mães de quatro crianças, assistidos na clínica privada por três psicoterapeutas treinados em psicoterapia psicanalítica. Eles responderam regularmente ao questionário de pergunta aberta que se centrou nas mudanças percebidas no curso do processo terapêutico. Os resultados mostraram que os pais têm identificado mudanças no curso da psicoterapia de seus filhos, que elas não eram lineares e não se limitaram à melhoria sintomática. Também se identificaram mudanças no funcionamento

* Universidade do Vale do Rio dos Sinos.

** Faculdades Meridionais, IMED.

*** Centro Universitário La Salle, Brasil.

Contacto principal para correspondencia editorial: Vera Regina Rohnelt Ramires, Universidade do Vale do Rio dos Sinos, Correio electrônico: verareginaramires@gmail.com

Para citar este artigo: Ramires, V. R. R., Carvalho, C., Gastaud, M. B., de Oliveira, L. R. F., \&, Rech, L. B. (2019). Mudanças na psicoterapia psicodinâmica de crianças na visão de pais e mães. Avances en Psicología Latinoamericana, 37(1), 29-46. Doi: http://dx.doi.org/10.12804/revistas.urosario.edu.co/apl/a.5458 
mental das crianças e sua adaptação à realidade, e nas relações interpessoais. Se discutiu a importância da participação dos pais na psicoterapia das crianças e o seguimento de sua visão acerca do processo terapêutico. Eles podem proporcionar feedbacks importantes que contribuem para o progresso do tratamento.

Palabras-chave: psicoterapia psicanalítica, mudanças, crianças.

\section{Resumen}

En el campo de la investigación en psicoterapia psicodinámica de los niños, una cuestión abierta es cómo evaluar sistemáticamente los cambios y cuáles se consideran fundamentales. No se han llevado a cabo análisis cualitativos acerca de la visión de padres y madres. El objetivo de este estudio fue investigar la percepción de padres y madres sobre los posibles cambios en sus niños durante sus psicoterapias. El estudio tuvo enfoque cualitativo, descriptivo, longitudinal. Los participantes fueron padres y madres de cuatro niños, atendidos en la clínica privada por tres psicoterapeutas entrenados en psicoterapia clínica. Ellos respondieron regularmente al cuestionario de pregunta abierta que se centró en los cambios percibidos en el curso del proceso terapéutico. Los resultados mostraron que los padres han identificado cambios en el curso de la psicoterapia de sus hijos, que ellos no eran lineales y no se limitaron a la mejoría sintomática. También se identificaron cambios en el funcionamiento mental de los niños y su adaptación a la realidad, y en las relaciones interpersonales. Se discutió la importancia de la participación de los padres en la psicoterapia de los niños y el seguimiento de su visión acerca del proceso terapéutico. Ellos pueden proporcionar feedbacks importantes que contribuyen para el progreso del tratamiento.

Palabras clave: psicoterapia psicoanalítica, cambios, niños.

\section{fibstract}

In child psychodynamic psychotherapy research, a remaining question is how to systematically evaluate changes and which ones are regarded as fundamental. Qualitative analyzes that contemplate the parents' view of such changes have not been undertaken. The aim of this study was to investigate the parents' perception of possible changes in school-age children during their psychotherapies. The study had a qualitative, descriptive, longitudinal design. The participants were the parents of four school-aged children, assisted in private clinic by three psychotherapists trained in psychoanalytic psychotherapy. They periodically answered to an open-ended questionnaire that focused on perceived changes during the therapeutic process. The results showed that fathers and mothers identified changes in the course of their children's psychotherapies, which were not linear and were not restricted to symptomatic improvements. Changes in children mental functioning and in their adjustment to reality, interpersonal relationships, have also been identified. The importance of parental participation in children's psychotherapy and the follow-up of their perceptions about the therapeutic process was discussed. They can provide important feedbacks that contribute to the progress of treatment.

Keywords: Psychoanalytic psychotherapy, change, children.

\section{Introdução}

A psicoterapia psicodinâmica ou psicanalítica (PP) de crianças é uma abordagem que visa abordar situações focais, identificar e resolver conflitos de desenvolvimento, facilitar a aquisição de insight sobre as motivações inconscientes de comportamentos relacionados aos principais conflitos e ajudar o paciente a retomar um curso normal de desenvolvimento (Henry P. Coppolillo, 1990; Joseph Sandler, 1982). Seu aspecto mais essencial é interpretar os impulsos e as defesas conflitantes do paciente. Esta técnica permite que o ego funcione de forma mais adaptada, tornando possível a 
modificação das defesas, uma mudança no superego e uma maior gratificação instintiva.

Teóricos da psicanálise e da PP de crianças descreveram critérios para se considerar o término do tratamento. Sandler (1982) postulou que tais critérios se relacionam com as metas analíticas, e que eles envolvem três grupos: a retomada do desenvolvimento normal da criança, o progresso do próprio trabalho analítico, incluindo a resolução da transferência e, finalmente, as conquistas fora do enquadre analítico, incluindo a adaptação da criança em casa e na escola. Para Coppolillo (1990), além disso, é importante notar quando a criança começa a mostrar um sentido definido e reconhecível de si mesma e maior plasticidade no seu funcionamento mental, diminuindo os modos rígidos e repetitivos de responder às demandas. $\mathrm{E}$ o quanto seus investimentos se tornaram mais positivos e esperançosos, surgindo novos interesses e atividades.

Paulina Kernberg et al. (2012) corroboraram tais critérios, salientando as mudanças no relacionamento da criança com o terapeuta e na qualidade de suas comunicações, com aumento de verbalizações, a aquisição de uma perspectiva de tempo, e o uso de defesas mais flexíveis e evoluídas. Maior autonomia e autoconfiança, assim como maior capacidade reflexiva sobre os próprios estados mentais e os dos outros, também foram mudanças descritas por esses autores.

Contudo, também é importante lembrar que cada paciente mostra uma trajetória de mudança e de crescimento única. Patrick Luyten, Sidney Blatt e Linda Mayes (2012) referem que o processo de mudança ou melhora na PP não é linear. As mudanças descritas por esses autores incluem mudanças na diferenciação, articulação e integração nas representações do objeto; mudanças nos estados da mente com relação às experiências de apego; mudanças nos sentimentos de segurança; representações do self e dos outros, mais diferenciadas e integradas; níveis mais altos de integração da identidade; desenvolvimento da função reflexiva ou mentalização; menos uso de mecanismos de defesa primitivos; aumento da capacidade de autoanálise; habilidade para experimentar novos comportamentos, especialmente em relacionamentos interpessoais; encontrar prazer em novos desafios; maior tolerância aos afetos negativos; e maior insight sobre como o passado pode determinar o presente. Evidentemente, tais possibilidades devem ser consideradas de acordo com a etapa de desenvolvimento emocional, cognitivo e social do paciente.

Hans Strupp (2013) também reuniu os critérios para se avaliar a mudança terapêutica em três grupos. Baseou-se na sistematização de Robert Knight elaborada há algumas décadas, inspirado pelo trabalho de psicanalistas como Otto Fenichel, James Strachey e Ernest Bibring, entre outros. Os critérios relatados por Strupp foram: (a) desaparecimento dos sintomas; (b) melhora efetiva no funcionamento mental (que inclui insight intelectual e emocional sobre os conflitos; tolerância, sem ansiedade, dos impulsos instintivos; autoaceitação, com avaliação acurada dos próprios potenciais e fragilidades; liberação equilibrada da agressividade necessária para autopreservação, conquistas, competição e garantia de direitos) e (c) ajustamento à realidade (que inclui relacionamentos interpessoais consistentes baseados numa escolha objetal saudável; livre utilização de habilidades; capacidade de sublimação; ajustamento psicossexual).

Todas as abordagens descritas até aqui oferecem parâmetros para os clínicos na apreciação das mudanças e das melhoras obtidas como resultado de uma PP. Também oferecem um enquadre para os pesquisadores interessados na investigação da efetividade ou eficácia desses tratamentos. Contudo, embora a pesquisa no campo da PP tenha tido um importante desenvolvimento nas últimas décadas, os estudos que se destinaram a examinar a PP com crianças ainda representam um número mais restrito. As revisões publicadas nos últimos anos indicaram que a PP produz mudanças clinicamente 
significativas (Nick Midgley \& Eilis Kennedy, 2011; Rose Palmer, Leonardo Niro Nascimento \& Peter Fonagy, 2013; John R. Weiz, Amanda Jensen Doss \& Kristin M. Hawley, 2005). Porém, os autores são unânimes em afirmar que muitos dos resultados não são conclusivos, ou os estudos revisados apresentavam problemas metodológicos, sendo necessárias novas pesquisas para que se compreendam as mudanças resultantes de uma PP.

Os estudos que analisaram os resultados da PP com crianças, em geral, adotaram medidas aplicadas diretamente à criança ou medidas respondidas pelos pais ou responsáveis, tais como o Child Behavior Checklist (CBCL), o Child Depression Inventory (CDI), o WISC-III, o Rorschach, o Bender, a Children's Global Assessment Scale (CGAS), Child Attachment Interview, MsArthur Story Stem Battery, entre outros instrumentos (Elizabeth Deakin \& Maria Lucia Nunes, 2009; Pia Eresund, 2007; Tine Heede, Hanne Runge, Ole Jacob Storebo, Eva Rowley \& Kim Gabriel Hansen, 2009; Fredrik Odhammar, Eva Sundin, Mathias Jonson \& Gunnar Calberg, 2011; Mary Target, Joan March, Karin Ensink, John Fabricius \& Peter Fonagy, 2002; Judith Trowell et al., 2007). Estas medidas buscam identificar mudanças nos sintomas apresentados pelas crianças (CBCL, CDI, CGAS), mudanças na organização e funcionamento da personalidade (Método de Rorschach), mudanças nas representações de apego (Child Attachment Interview, MsArthur Story Stem Battery), ou mudanças em fatores específicos como inteligência verbal e não verbal, desenvolvimento psicomotor (WISC-III, Bender).

Alguns estudos analisaram as mudanças na perspectiva da criança por meio de entrevistas e desenhos (Claudia Capella et al., 2015), ou suas expectativas e experiências em relação à PP descritas a partir de entrevistas semiestruturadas com instrumentos de auto avaliação, material de desenho e uma seleção de brinquedos (Gunnar Calberg, Agneta Thorén, Susanna Billstrom \& Fredrik Odhammar, 2009). Outros exploraram a perspectiva dos terapeutas, utilizando entre- vistas em profundidade e questionários (Daniela Águila et al., 2016; Calberg, 2009; Odhammar \& Calberg, 2015). Odhammar e Calberg (2015) também analisaram os objetivos formulados pelos pais para a psicoterapia dos seus filhos. Com base nos questionários respondidos pelos pais, as categorias formuladas incluíram o desenvolvimento psicológico da criança, a redução dos sintomas, o relacionamento da criança com as outras pessoas, as relações entre a criança e os pais, e ajuda para o seu próprio bem-estar e para a família, incluindo orientação. Porém, o foco deste estudo foi sobre as expectativas de mudança, e não sobre as mudanças efetivamente percebidas como resultado da psicoterapia.

A psicoterapia de crianças envolve necessariamente seus pais ou responsáveis, e esse é um fator que implica uma dinâmica específica e complexa para tais processos terapêuticos (Luiz Ronaldo Freitas de Oliveira, Marina Gastaud \& Vera Regina Rohnelt Ramires, 2016). Michele Roman Faria (2016) e Ana Maria Sigal de Rosenberg (2002) discutiram a importância do terapeuta levar em conta o lugar que a criança e os seus sintomas ocupam na família e no inconsciente dos pais. A relação entre o casal parental, assim como o lugar da criança e seus sintomas no psiquismo dos pais são questões inerentes ao processo terapêutico com essa população, com implicações para a abordagem técnica e os movimentos de mudança, progressos e retrocessos.

Segundo Oliveira, Gastaud e Ramires (2016), não há consenso na literatura sobre como deve se dar a participação dos pais, havendo abordagens mais ou menos intervencionistas e mais ou menos inclusivas. Contudo, os autores observam que há uma tendência crescente na literatura da sua valorização. Além disso, uma questão que permanece é como avaliar sistematicamente as mudanças na PP, e quais são consideradas fundamentais (Luyten et al., 2012). É importante não apenas que se utilizem diferentes instrumentos, abordando suas várias dimensões, mas também que essa análise 
seja feita com base em diferentes perspectivas dos informantes envolvidos no processo terapêutico. Análises qualitativas que contemplem a visão dos pais acerca de tais mudanças não têm sido empreendidas (Lilian Pereira de Medeiros Guimarães \& Elisa Médici Pizão Yoshida, 2014). Com base em tais premissas, o objetivo deste estudo foi investigar a percepção dos pais acerca de possíveis mudanças em crianças em idade escolar no decorrer das suas psicoterapias psicodinâmicas. As hipóteses investigadas foram: a) Seria possível para os pais identificar e descrever mudanças em seu/sua filho(a) no decorrer da PP, tanto no sentido de progressos como de eventuais retrocessos, especialmente nos tratamentos de longa duração; e b) as mudanças identificadas corresponderiam tanto ao nível dos sintomas e comportamentos como do bem-estar e desenvolvimento psicológico da criança.

\section{Método}

O estudo teve uma abordagem qualitativa, descritiva, longitudinal, utilizando-se de medida repetida.

\section{Participantes}

Os participantes do estudo foram os pais e mães de quatro crianças em idade escolar, atendidas em consultórios particulares em PP individual, por três psicoterapeutas do sexo feminino, com formação em PP. Essa formação incluiu seminários teóricos, supervisão e tratamento pessoal. Uma terapeuta atendeu duas crianças, e o tempo de experiência era de dois anos, 10 anos e 23 anos no início dos atendimentos. A tabela a seguir sintetiza algumas características dos participantes e dos tratamentos.

\section{Instrumento}

Foi utilizado o "Questionário que focaliza temas importantes e mudanças a cada três meses de psicoterapia - versão para pais", desenvolvido por Calberg (2009), para utilização em estudo com terapeutas e pais de 19 crianças suecas com idades entre 5 e 10 anos que realizaram PP devido a problemas de atenção, desordens do comportamento disruptivas e transtornos de ansiedade. É um instrumento com pergunta aberta, respondido por cada genitor da criança. Solicita-se que pen-

Tabela 1.

Caracterização dos participantes e das psicoterapias

\begin{tabular}{|c|c|c|c|c|}
\hline & Caso 1 - Walter* & Caso 2 - Pedro & Caso 3 - Antônio & Caso 4 - Alice \\
\hline $\begin{array}{l}\text { Mãe - idade, grau de instrução, } \\
\text { profissão }\end{array}$ & $\begin{array}{l}32 \text { anos, superior in- } \\
\text { completo, consultora } \\
\text { de vendas }\end{array}$ & $\begin{array}{l}36 \text { anos, superior, } \\
\text { funcionária pública }\end{array}$ & $\begin{array}{l}36 \text { anos, superior, } \\
\text { funcionária pública }\end{array}$ & $\begin{array}{l}38 \text { anos, } 2^{\circ} \text { grau, } \\
\text { secretária }\end{array}$ \\
\hline $\begin{array}{l}\text { Pai - idade, grau de instrução, } \\
\text { profissão }\end{array}$ & $\begin{array}{l}35 \text { anos, } 2^{\circ} \text { grau, } \\
\text { comerciante }\end{array}$ & $\begin{array}{l}38 \text { anos, superior, } \\
\text { profissional liberal }\end{array}$ & $\begin{array}{l}42 \text { anos, superior, } \\
\text { profissional liberal }\end{array}$ & Falecido aos 40 anos \\
\hline $\begin{array}{l}\text { Idade da criança início psico- } \\
\text { terapia }\end{array}$ & 7 anos & 8 anos & 9 anos & 8 anos \\
\hline Diagnóstico & $\begin{array}{l}\text { Transtorno Disruptivo } \\
\text { da Desregulação do } \\
\text { Humor }\end{array}$ & $\begin{array}{l}\text { Síndrome de As- } \\
\text { perger }\end{array}$ & $\begin{array}{l}\text { Transtorno de An- } \\
\text { siedade }\end{array}$ & $\begin{array}{l}\text { Transtorno de Adap- } \\
\text { tação }\end{array}$ \\
\hline $\begin{array}{l}\text { Tempo de psicoterapia / } n^{\circ} \text { de } \\
\text { sessões }\end{array}$ & $\begin{array}{l}44 \text { meses } \\
160 \text { sessões }\end{array}$ & $\begin{array}{l}43 \text { meses } \\
151 \text { sessões }\end{array}$ & $\begin{array}{l}22 \text { meses } \\
58 \text { sessões }\end{array}$ & $\begin{array}{l}15 \text { meses, } \\
40 \text { sessões }\end{array}$ \\
\hline $\begin{array}{l}\text { Tempo de experiência terapeu- } \\
\text { ta início psicoterapia }\end{array}$ & 23 anos & 2 anos & 3 anos & 10 anos \\
\hline
\end{tabular}

* Os nomes foram modificados, assim como qualquer informação que permitisse identificar os participantes. 
se sobre os últimos três meses de psicoterapia e responda à questão: qual foi a mudança mais importante no período? Solicita-se que especifique: quando a mudança ocorreu e que a descreva o mais cuidadosamente possível; o que foi novo na mudança; e as circunstâncias e fatores significativos que podem ter sido subjacentes.

\section{Procedimentos}

Os pais procuraram psicoterapia para seus filhos e iniciaram o processo de avaliação. Todas as avaliações foram realizadas nos consultórios das psicoterapeutas e foram baseadas em entrevistas com os pais, horas de jogo diagnósticas com as crianças, Método de Rorschach e preenchimento do CBCL pelos pais e professoras das crianças.

Confirmada a indicação para a psicoterapia e contratado seu início com os pais e as crianças, as terapeutas informaram a todos sobre a pesquisa. As terapeutas já haviam sido previamente consultadas e concordaram em participar. A participação na pesquisa era opcional, e não constituía condição para realização dos tratamentos. Tendo concordado, os pais assinaram o Termo de Consentimento Livre e Esclarecido e foram informados sobre todas as implicações da pesquisa, o direito de retirar seu consentimento a qualquer momento, sem prejuízo da psicoterapia e de solicitar quaisquer informações que lhes parecessem necessárias. $\mathrm{O}$ estudo foi aprovado por Comitê de Ética em Pesquisa da Universidade do Vale do Rio dos Sinos, datado de 11/05/2012, com base na Resolução 196/1996 do Conselho Nacional de Saúde, sob o parecer 039/2012.

A cada três meses, as terapeutas recebiam da equipe de pesquisa uma via impressa do questionário para a mãe e para o pai do paciente, e as entregava para eles, que deveriam responder e devolvê-las. Esse processo nem sempre correspondeu ao intervalo de três meses, havendo atrasos na entrega dos questionários para os pais ou na devolução dos mesmos por parte deles.
Os questionários de cada caso foram submetidos a uma análise de conteúdo que seguiu as diretrizes de Egberto Ribeiro Turato (2003). Cada questionário foi lido por dois pesquisadores com experiência em PP de crianças. Suas classificações foram, posteriormente, comparadas para verificação da concordância e formulação das categorias finais, identificadas no conjunto dos 24 questionários dos quatro casos.

\section{Resultados}

Inicia-se com uma breve descrição de cada caso, para então apresentar a visão dos pais e mães acerca das mudanças percebidas no decorrer das psicoterapias.

\section{Caso 1 - Walter}

Os pais de Walter buscaram psicoterapia devido às suas dificuldades de relacionamento na escola. Ele estava na $1^{\text {a }}$ série, não tinha amigos, e seus colegas costumavam implicar com ele. Segundo a mãe, Walter era muito impulsivo. Na última briga em sala de aula jogou uma mesa sobre um colega. No ano anterior, sofreu bullying e foi transferido para outra turma.

Walter era filho único, e apresentava um comportamento infantil e regressivo. Ainda usava mamadeira e dormia no quarto de seus pais. Recusava-se a realizar as tarefas escolares.

A psicoterapia teve duração de 44 meses, com duas sessões semanais de 50 minutos. Walter era dependente, pedindo à terapeuta para ajudá-lo a tirar seus sapatos ou casaco ou ajudá-lo quando ia ao banheiro. Ele também exibiu comportamento dominante em direção à terapeuta, tentando dar ordens, e fazendo uma série de demandas. Costumava expressar fortes sentimentos de irritação, comportamentos agressivos e explosões de raiva. Foi diagnosticado com Transtorno Disruptivo da Desregulação do Humor (TDDH) (American Psychiatric Association, APA, 2014). 
Ao longo do tratamento, foi difícil para Walter examinar seus problemas na escola e reconhecer seus sentimentos, especialmente no que diz respeito à sua agressividade e medos. Parecia incapaz de lidar com esses momentos, pedia à terapeuta para parar de falar e se escondia debaixo de uma mesa ou atrás de uma cadeira.
No decorrer do tratamento, devido às dificuldades de Walter no cumprimento das tarefas escolares, a escola encaminhou o menino para acompanhamento psicopedagógico. A pedagoga, além do seu trabalho com o menino, encaminhou-o para acompanhamento psiquiátrico e durante um período Walter foi medicado. Na avaliação da sua terapeuta, o menino não apresentava dificulda-

Tabela 2.

Mudanças de Walter no decorrer da sua psicoterapia na visão da sua mãe e de seu pai

\begin{tabular}{|c|c|c|c|}
\hline Avaliação & $\begin{array}{c}\text { Tempo } \\
\text { Psicoterapia }\end{array}$ & Visão da Mãe & Visão do Pai \\
\hline Q1 & 6 meses & $\begin{array}{l}\text { Largou a mamadeira, o que resultou em mais } \\
\text { autoconfiança }\end{array}$ & $\begin{array}{l}\text { Mais concentrado nas tarefas escolares; } \\
\text { Mais confiante; } \\
\text { Mais entrosado com colegas. }\end{array}$ \\
\hline Q2 & 12 meses & $\begin{array}{l}\text { Mais autônomo ao vestir-se, banhar-se, etc.; } \\
\text { Mais seguro em relação à opinião dos pares; } \\
\text { Diminuição das mudanças abruptas de tempera- } \\
\text { mento; menos agressivo; } \\
\text { Ainda se sente infeliz na escola; } \\
\text { Às vezes não completa tarefas escolares. }\end{array}$ & $\begin{array}{l}\text { Melhor relacionamento com colegas e profes- } \\
\text { sores; } \\
\text { Não reage às provocações dos colegas; } \\
\text { Mais cooperativo no judô. }\end{array}$ \\
\hline Q3 & 20 meses & $\begin{array}{l}\text { Melhora no acolhimento da escola após visita } \\
\text { da psicóloga; } \\
\text { Mais socializado e participativo na escola. }\end{array}$ & $\begin{array}{l}\text { Mais socializado e participativo na escola; } \\
\text { Mais rendimento nas tarefas escolares. }\end{array}$ \\
\hline Q4 & 25 meses & $\begin{array}{l}\text { Agressões a colegas e professores cessaram } \\
\text { após troca de escola; } \\
\text { Período intenso de estudos para acompanhar } \\
\text { conteúdos na nova escola; } \\
\text { Entrosamento gradativo com os pares no novo } \\
\text { ambiente. }\end{array}$ & $\begin{array}{l}\text { Mais autoconfiante; } \\
\text { Desejo de passar de ano; } \\
\text { Menos sozinho na escola. }\end{array}$ \\
\hline Q5 & 32 meses & $\begin{array}{l}\text { Regressão na escola; busca por atendimento } \\
\text { psicopedagógico e psicofarmacológico; } \\
\text { Mais calmo; } \\
\text { Mais preocupação com os outros; } \\
\text { Mais interação com colegas fora da escola. }\end{array}$ & $\begin{array}{l}\text { Medicação ajudou; } \\
\text { Mais dedicação na escola; } \\
\text { Mais interação com colega e amigos; } \\
\text { Recebeu elogios da professora. }\end{array}$ \\
\hline Q6 & 40 meses & $\begin{array}{l}\text { Tranquilo nas férias e no retorno à escola; } \\
\text { Queixas de dor de cabeça; preocupações de ter } \\
\text { doença grave; } \\
\text { Relacionamento bom com colegas; } \\
\text { Permanece dificuldade em completar tarefas } \\
\text { escolares; }\end{array}$ & $\begin{array}{l}\text { Melhor relacionamento com colegas; } \\
\text { Melhor desempenho nas tarefas escolares. }\end{array}$ \\
\hline Q7 & 44 meses & $\begin{array}{l}\text { Reagiu com segurança à separação dos pais; } \\
\text { Boa interação com colegas; } \\
\text { Expressa mais seus sentimentos e pensamentos; } \\
\text { Permanecem dificuldades para concluir tarefas } \\
\text { escolares, mas quando quer se sai muito bem. }\end{array}$ & $\begin{array}{l}\text { Mais independente; } \\
\text { Boa interação com colegas; } \\
\text { Permanecem dificuldades para concluir tarefas } \\
\text { escolares, mas se sai bem nas provas. }\end{array}$ \\
\hline
\end{tabular}

Nota: Q1 = Questionário 1, Q2 = Questionário 2 e assim por diante. 
des de aprendizagem, possuindo boas condições cognitivas.

A abordagem teórica adotada pela terapeuta foi baseada na psicoterapia psicodinâmica, inspirada principalmente na teoria das relações de objeto. Ela também usou elementos da abordagem proposta por Paulina Kernberg \& Saralea Chazan (1991) para crianças com transtornos de conduta, que abrange intervenções de suporte e expressivas.

A mesma terapeuta realizou 25 entrevistas periódicas de acompanhamento com os pais para ouvir suas ansiedades e preocupações, fornecer orientação e coletar informações adicionais. A terapeuta também manteve contato com a escola da criança, a fim de ajudar a ampliar sua compreensão das dificuldades do menino nesse ambiente.

Durante o processo terapêutico, os pais de Walter se separaram e o menino mudou de escola. No final do tratamento, havia consenso entre todos acerca da sua significativa evolução, superação das dificuldades e amadurecimento. A tabela 2 apresenta a síntese das respostas dos pais aos sete questionários respondidos durante sua psicoterapia.

\section{Caso 2 - Pedro}

Pedro tinha oito anos quando seus pais buscaram ajuda terapêutica. Eles estavam preocupados com o desempenho do filho na escola. Recebiam queixas porque não realizava as tarefas escolares. O menino cursava a $2^{\mathrm{a}}$ série, não tinha irmãos e também exibiam sintomas de ansiedade e vários medos: de ficar sozinho, que a mãe saísse e não voltasse. O casal havia se separado recentemente, e os sintomas de Pedro foram percebidos nessa época.

Nas suas sessões, o menino mostrava-se bastante retraído, quase não falava. Escolhia jogar sempre o mesmo jogo de tabuleiro. A interação com a terapeuta era muito pobre, respondendo às suas intervenções sempre com um "não sei". A terapeuta sentia que sua inclusão no jogo se dava pela necessidade do paciente de ter alguém para jogar, mas que parecia ser insignificante ou mesmo inexistente para ele. Pedro foi diagnosticado com Transtorno de Asperger (de acordo com o DSM-5 [APA, 2014], o diagnóstico seria Transtorno do Espectro Autista, nível 1, sem prejuízo da linguagem e intelectual concomitantes).

Com o tempo, Pedro começou a demonstrar, de modo contido, alguma contrariedade quando perdia o jogo. Nessa época, a família recebeu a notícia da doença séria de um familiar próximo, o que passou a constituir um segredo familiar, não comunicado ao menino. Pedro expressou desconfianças nesse período, em relação à terapeuta, achando que faltavam peças no jogo ou que ela pudesse ter trapaceado de alguma forma quando ele perdia. Começou a ir para o banheiro durante as suas sessões, ali permanecendo por mais de 15 minutos.

Como intervenções interpretativas não produziam qualquer efeito, a terapeuta passou a interagir com ele de maneira mais ativa e mais lúdica, com o objetivo de que, através da brincadeira e de um contexto de relacionamento seguro e confiável, pudesse ajudá-lo a se reconhecer como pessoa única, com uma identidade própria, e descobrir e compreender seus sentimentos, pensamentos, desejos, propiciando, com isso, o desenvolvimento de um funcionamento mais reflexivo. Essa estratégia seguiu as diretrizes da psicoterapia baseada na mentalização, que visa promover a organização do self do paciente, reconhecendo-se como uma pessoa que tem uma mente dotada de estados mentais a serem identificados e compreendidos (Annelies Verheugt-Pleiter, Jolien Zevalnkink \& Marcel Schmeets, 2008).

Apresentando-se como uma companhia real e viva para o paciente e expressando emoções de alegria ao vencer o jogo e desapontamento ao perder, a terapeuta abriu espaço para que o paciente, gradativamente, pudesse fazer o mesmo, permitindo-se expressar o que sentia. A psicoterapia passou a ter frequência de duas sessões semanais. Para cada etapa em que iam avançando, 
Tabela 3.

Mudanças de Pedro no decorrer da sua psicoterapia na visão da sua mãe e de seu pai

\begin{tabular}{|c|c|c|c|}
\hline Avaliação & $\begin{array}{c}\text { Tempo } \\
\text { Psicoterapia }\end{array}$ & Visão da Mãe & Visão do Pai \\
\hline Q1 & 4 meses & $\begin{array}{l}\text { Mais solto, e conseguindo ficar longe da mãe; } \\
\text { Disposto a provar novos alimentos; } \\
\text { Curioso e fazendo muitas perguntas sobre a sepa- } \\
\text { ração dos pais. }\end{array}$ & $\begin{array}{l}\text { Consegue expressar mais seus sentimentos e } \\
\text { suas contrariedades; } \\
\text { Consegue se negar a fazer algo que não queira; } \\
\text { Melhor desempenho na escola, }\end{array}$ \\
\hline Q2 & 7 meses & $\begin{array}{l}\text { Expressa mais seus sentimentos, } \\
\text { Começa a perceber que é super exigente; } \\
\text { Mais afetuoso e espontâneo, mais alegre e à von- } \\
\text { tade; } \\
\text { Pela primeira vez não apanhou quieto na escola e } \\
\text { revidou; } \\
\text { Ainda é muito "agarrado" à mãe e não quer ficar } \\
\text { sozinho. }\end{array}$ & $\begin{array}{l}\text { Expressa mais e melhor suas emoções, con- } \\
\text { trariedades e vontades; } \\
\text { Autoestima melhorando, mas ainda se mos- } \\
\text { tra aborrecido quando erra; } \\
\text { Mais seguro em relação à manutenção do } \\
\text { vínculo com pai após a separação do casal; } \\
\text { Reagiu numa briga com colega que costuma- } \\
\text { va bater nele, }\end{array}$ \\
\hline Q3 & 12 meses & $\begin{array}{l}\text { Mudou após tentativa de reaproximação do pai em } \\
\text { relação à mãe; ansiedade e expectativa; } \\
\text { Notícia de doença na família abalou a mãe; dificul- } \\
\text { dade para se separar; quer dormir com a mãe; } \\
\text { Falta de atenção na escola. }\end{array}$ & Não respondeu. \\
\hline Q4 & 15 meses & $\begin{array}{l}\text { Progressos na escola: mais focado, atento e respon- } \\
\text { sável com as tarefas; } \\
\text { Empatia com a nova turma e professora; fez amigos; } \\
\text { Às vezes fica bravo e com raiva e quer jogar as } \\
\text { coisas longe. }\end{array}$ & $\begin{array}{l}\text { Mudança significativa na escola, mais con- } \\
\text { centração, melhor desempenho e notas; } \\
\text { Sente o filho mais próximo; } \\
\text { Reclama da mãe. }\end{array}$ \\
\hline Q5 & 22 meses & $\begin{array}{l}\text { Menos ansioso; } \\
\text { Demonstra mais os sentimentos; } \\
\text { Mais atento na escola. }\end{array}$ & $\begin{array}{l}\text { Mais alegre e espontâneo; } \\
\text { Demonstra melhor seus sentimentos; } \\
\text { Melhorou sensivelmente na escola. }\end{array}$ \\
\hline Q6 & 26 meses & $\begin{array}{l}\text { Demonstra mais seus sentimentos e vontades; } \\
\text { Mais atento em aula e nos estudos. }\end{array}$ & Não respondeu. \\
\hline Q7 & 30 meses & $\begin{array}{l}\text { Mais rebelde, resistente com regras, "respondão" e } \\
\text { agressivo; } \\
\text { Reclamações de ter passado pouco tempo com pai } \\
\text { nas férias. }\end{array}$ & $\begin{array}{l}\text { Saindo da infância e entrando na pré-adoles- } \\
\text { cência; } \\
\text { Na escola boa evolução, embora persistam } \\
\text { problemas de atenção. }\end{array}$ \\
\hline Q8 & 36 meses & $\begin{array}{l}\text { Melhora grande na escola, mais comprometido; } \\
\text { notas excelentes; } \\
\text { Mais seguro; superou medo de ficar sozinho; } \\
\text { Começou a praticar natação; } \\
\text { Teimoso com a mãe ("parece adorar discutir comigo"); } \\
\text { Começou a dizer que não precisa mais fazer terapia } \\
\text { e não quer mais ir. }\end{array}$ & $\begin{array}{l}\text { Passando da infância para pré-adolescência; } \\
\text { Mudança de interesses, inclusive na escola } \\
\text { (conversa mais sobre o que aprende); } \\
\text { Mais interesse em conversar sobre seus sen- } \\
\text { timentos e ideias. }\end{array}$ \\
\hline Q9 & 43 meses & $\begin{array}{l}\text { Mais maduro e seguro de si, mais confiante, mais } \\
\text { feliz e satisfeito; } \\
\text { Desempenho muito bom na escola; } \\
\text { Consegue demonstrar e conversar sobre o que sente, } \\
\text { sobre emoções, vontades e inconformidades; } \\
\text { Menos preocupação em agradar os outros, princi- } \\
\text { palmente a mãe. }\end{array}$ & $\begin{array}{l}\text { Chegada da puberdade; alterna comporta- } \\
\text { mentos infantis e pré-adolescentes; } \\
\text { Demonstra mais seus sentimentos e contra- } \\
\text { riedades; } \\
\text { Mais interessado e participativo na escola. }\end{array}$ \\
\hline
\end{tabular}


primeiro do brincar, depois de identificar, nomear e expressar os sentimentos, a terapeuta sentia que Pedro precisava de um período de "sedimentação", para que, somente depois, pudessem avançar na exploração do conteúdo mental.

Por volta do terceiro ano de tratamento, Pedro começou a trazer para o setting as dificuldades no relacionamento com a mãe, o medo que sentia de perder os pais, atividades da escola e assuntos gerais que lembrava enquanto conversavam ou jogavam. Começou a relatar sonhos que foram associados ao seu medo de perder os pais e ficar desamparado.

Nesse período, Pedro se mostrava mais espontâneo, e incluía mais a terapeuta em seu jogo e na sua fala. Passou a chamá-la pelo nome, o que não havia acontecido até então. Começou a se arriscar, a fazer coisas diferentes. Expressava melhor o que sentia e o que pensava. Conquistou alguns amigos na escola. Começou a expressar o desejo de encerrar o tratamento, o que ocorreu após 43 meses de psicoterapia.

Ao longo da psicoterapia, foram realizadas 19 entrevistas com os pais de Pedro, duas apenas com a mãe e três apenas com o pai. A tabela 3 mostra as mudanças de Pedro no decorrer desse período, de acordo com a visão de seus pais.

\section{Caso 3 - Antônio}

Antônio tinha nove anos no início da psicoterapia, cursava a $3^{\mathrm{a}}$ série do Ensino Fundamental e residia com sua mãe, pai e irmão mais novo. Os pais buscaram atendimento devido a seu comportamento agressivo. Relataram que Antônio não fazia o que lhe era demandado e quando era cobrado, dizia que "os pais eram chatos, que só brigavam com ele e não gostavam dele" (sic). Antônio era o filho mais velho do casal e vinha agindo de forma agressiva e opositora, desde que identificaram que $o$ filho mais novo necessitava de cuidados especiais, em função de apresentar "traços autistas". Isso tomava todo o tempo deles, gerando reclamações por parte de Antônio, que reclamava de falta de atenção e que só o irmão recebia cuidados.

Segundo a mãe, Antônio era tímido, roía as unhas, não aceitava perder quando jogava com os amigos ou com a família e ficava muito bravo quando isso acontecia. Antônio gostava muito de futebol e, se os pais deixassem, faria isso o tempo todo. A mãe também relatou ser uma pessoa perfeccionista, queixando-se muito da falta de ajuda do pai. O pai disse "estar sempre cansado quando chegava em casa, queixando-se das exigências da mãe" (sic). Não fazia atividades com os filhos. O casal relatou brigar muito, inclusive na presença dos filhos.

No processo psicoterápico, Antônio mostrou-se uma criança tímida, retraída e silenciosa. Ao chegar, sentava-se na poltrona, esperando que a terapeuta iniciasse a sessão. Mexia as mãos, respondia ao que lhe era perguntado de forma rápida e bastante sucinta. Foi diagnosticado com Transtorno de Ansiedade Generalizada (APA, 2014).

Após estímulo da terapeuta, Antônio explorou o consultório, jogou Xadrez e Jogo da Vida. Desde o início, mostrou preferência pelo jogo de futebol de botões. Ao longo do tempo, expressou a falta que sentia do pai, reclamando que o mesmo nunca tinha tempo disponível para ele. Também relatou que se incomodava com seu irmão, pois tinha de fazer muitas coisas em função dele. Sentia-se exigido pela mãe, no que dizia respeito à escola, à organização da casa e aos cuidados com o irmão.

No decorrer do tratamento, Antônio passou a ficar mais competitivo. Passou a escolher, quase sempre, o jogo de botões. As tentativas da terapeuta de explorar o significado do jogo e a necessidade de ganhar não surtiam efeito. Ao longo do tempo, também se tornou mais retraído e contido nas sessões. Evitava falar sobre seus sentimentos e pensamentos, adotando um distanciamento maior na relação terapêutica e se defendendo contra materiais que sentia como perturbadores.

A ansiedade de Antônio foi aumentando e alguns sintomas obsessivos começaram a ficar evi- 
dentes. O paciente fechava os olhos para não ver uma jogada, batia na mesa para dar sorte, punia-se quando errava. Negava ou ignorava as intervenções da terapeuta, desejando apenas jogar. Parecia estar buscando um maior controle das suas emoções e evitar se deparar com elas. As interpretações da sua resistência e defesas não surtiram efeito.

Após 22 meses de psicoterapia, em função de uma mudança de cidade da terapeuta, ela encaminhou Antônio para outra profissional, para que pudesse continuar sua psicoterapia. No entanto, pelas informações obtidas junto à profissional, a família e o menino não buscaram esse atendimento.
Ao longo da psicoterapia, foram realizadas sete entrevistas com os pais de Antônio, mais uma apenas com a mãe e uma apenas com o pai. A tabela 4 descreve as mudanças de Antônio percebidas por sua mãe no decorrer da psicoterapia.

\section{Caso 4 - Alice}

Alice tinha oito anos de idade no início da psicoterapia e foi encaminhada por sua médica neuropediatra. Apresentava dores de cabeça e estômago sem causas orgânicas. Os sintomas haviam iniciado imediatamente após a morte inesperada do pai, há

Tabela 4.

Mudanças de Antônio no decorrer da sua psicoterapia na visão da sua mãe e de seu pai

\begin{tabular}{|c|c|c|c|}
\hline Avaliação & $\begin{array}{c}\text { Tempo } \\
\text { Psicoterapia }\end{array}$ & Visão da Mãe & Visão do Pai \\
\hline Q1 & 4 meses & $\begin{array}{l}\text { Começou a pedir para os pais não gritarem durante suas bri- } \\
\text { gas; } \\
\text { Passou a gritar menos; } \\
\text { Fica mais calmo longe do pai nas férias (casal brigava muito } \\
\text { antes); } \\
\text { Conversa mais com a mãe; } \\
\text { Continua reclamando que o pai só grita com ele e não com o } \\
\text { irmão. }\end{array}$ & Não respondeu. \\
\hline Q2 & 7 meses & $\begin{array}{l}\text { Não houve mudanças significativas; } \\
\text { Continua agressivo e gritão. }\end{array}$ & Não houve mudanças aparentes. \\
\hline Q3 & 11 meses & $\begin{array}{l}\text { Há um mês está mais calmo, sem dizer a todo momento para a } \\
\text { mãe que a odeia quando contrariado; } \\
\text { Ficou sem videogame, celular e facebook por estar "respon- } \\
\text { dão" e então começou a melhorar; } \\
\text { Retomou tarefas escolares que estavam bastante desorganiza- } \\
\text { das; } \\
\text { Está melhor com a mãe, conversando e contando mais as coi- } \\
\text { sas da escola. }\end{array}$ & Não respondeu. \\
\hline Q4 & 15 meses & $\begin{array}{l}\text { Mais calmo com os amigos, consegue conversar, brincar e } \\
\text { jogar sem ficar ansioso ou eufórico; } \\
\text { Ainda se irrita quando contrariado; } \\
\text { Diz que odeia a mãe, que é a pior mãe do mundo; } \\
\text { Está ficando adolescente, mudou relação com amigos e não } \\
\text { quer ir a determinados lugares. }\end{array}$ & Nada mudou. \\
\hline Q5 & 22 meses & $\begin{array}{l}\text { Conversa mais com a mãe, contando coisas da aula e sobre } \\
\text { seus sentimentos quando os pais brigam com ele; } \\
\text { Mais maduro e autônomo, pega um ônibus para ir para casa } \\
\text { depois da aula e faz suas tarefas; está gostando disso, não que- } \\
\text { ria mais ficar na escola no turno inverso. }\end{array}$ & Não respondeu. \\
\hline
\end{tabular}

Nota: Q1 = Questionário 1, Q2 = Questionário 2 e assim por diante. 
cinco meses. Alice era bastante apegada ao pai e ele a ela. Após sua morte, a família sofreu abalo financeiro e a menina precisou mudar de escola. Alice estava no $3^{\circ}$ ano do Ensino Fundamental e residia com sua mãe e irmã mais nova.

A paciente não conseguia se adaptar à nova escola: sentia dificuldade de fazer novos amigos, saudade dos colegas antigos, fazia críticas constantes à falta de ordem da escola pública, chorava muito e relutava em ir às aulas. Segundo a mãe e a professora, Alice era uma criança carinhosa, perfeccionista e não tolerava errar, ficando ansiosa quando chamavam sua atenção. A terapeuta percebia em diversos momentos, ao longo das sessões, a vontade da menina em agradar, ser elogiada e querida. Alice foi diagnosticada com Transtorno de Adaptação (APA, 2014).

Em suas sessões, que se estenderam pelo período de 15 meses, Alice demonstrava capacidade de reflexão e criatividade nas brincadeiras, usando o jogo simbólico. Seu tratamento teve momentos fortemente alicerçados na interpretação da transferência, principalmente no período de gravidez da terapeuta (que ocorreu durante o processo). Sentimentos da paciente sobre a gravidez possibilitaram o trabalho de conflitos familiares, experiências de separação (do pai, dos colegas antigos, a separação futura da terapeuta), angústias obsessivas e fantasias sexuais infantis.

A maior parte da psicoterapia teve frequência semanal; o tratamento teve diversas interrupções em função de férias e da licença maternidade da terapeuta. Em seu retorno, foi realizada uma entrevista com a mãe e com a paciente em conjunto, quando foi decidida a interrupção da psicoterapia. Segundo a mãe, a menina havia superado os sintomas que apresentava no início do tratamento. Além disso, durante a pausa da terapia, a família passou a enfrentar novas dificuldades financeiras e a avó, que cuidava de Alice, adoeceu gravemente. O pagamento da psicoterapia ficou impossibilitado e a família não contava mais com um adulto dis- ponível para acompanhar a menina ao consultório da terapeuta para suas sessões.

Alice desejava manter o tratamento, mas reconhecia estar se sentindo melhor e entendia as dificuldades de manter a terapia. A terapeuta salientou alguns pontos que ainda precisavam ser trabalhados, mas reconheceu e valorizou as conquistas da paciente até o momento. $\mathrm{O}$ valor e a frequência das sessões finais foram renegociados, de forma que a dupla paciente-terapeuta pudesse trabalhar a separação. As últimas sete sessões da psicoterapia foram voltadas para este foco.

Ao longo da psicoterapia, foram realizadas oito entrevistas com a mãe de Alice, além da entrevista conjunta entre terapeuta, mãe e menina. A tabela 5 revela as mudanças de Alice no decorrer da psicoterapia, de acordo com sua mãe.

\section{Discussão}

Com base no relato clínico dos quatro casos e nos questionários respondidos pelos pais e mães, constatou-se que três desses tratamentos apresentaram uma evolução favorável, que culminou na alta das crianças, seja ela consensual (como no caso 1), seja ela uma alta a pedido (como nos casos 2 e 4). No caso 3, tanto a evolução da psicoterapia relatada pela terapeuta como as respostas aos questionários fornecidas pelos pais, mostraram um tratamento que não teve um desenvolvimento favorável.

Embora os questionários não tenham sido respondidos a cada três meses, como inicialmente previsto, a periodicidade obtida permitiu acompanhar a visão dos pais e mães das crianças, relativas às suas mudanças, melhoras e, eventualmente, regressões. Não é possível atribuir tais melhoras e retrocessos exclusivamente à psicoterapia, devido ao delineamento deste estudo. Além disso, deve-se considerar que em tratamentos longos como nos casos de Walter e Pedro, fatores do desenvolvimento e do contexto familiar, escolar e social, também contribuem para produzir efeitos, nos dois sentidos. 
Tabela 5.

Mudanças de Alice no decorrer da sua psicoterapia na visão da sua mãe

\begin{tabular}{|c|c|c|}
\hline Avaliação & $\begin{array}{c}\text { Tempo } \\
\text { Psicoterapia }\end{array}$ & Visão da Mãe \\
\hline Q1 & 3 meses & $\begin{array}{l}\text { Cessaram suas dores de cabeça; } \\
\text { Mais tranquila quanto à escola, } \\
\text { faz questão de não faltar; } \\
\text { Mais sociável, conversa, conta as } \\
\text { coisas e o que não gosta. }\end{array}$ \\
\hline Q2 & 8 meses & $\begin{array}{l}\text { Primeiro teve grandes mudanças: } \\
\text { dores de cabeça diminuíram, } \\
\text { mais segura, interagiu mais com } \\
\text { colegas; } \\
\text { Nos últimos } 2 \text { meses regrediu em } \\
\text { algumas coisas: períodos de do- } \\
\text { res de cabeça, sensação de perda } \\
\text { (medo que a avó morresse), só } \\
\text { queria ficar com a mãe; } \\
\text { Apareceu coceira no corpo; } \\
\text { Fala muito no pai; } \\
\text { Ajuda muito a avó nas atividades } \\
\text { de casa e nos cuidados dela; } \\
\text { Necessidade grande de agradar, } \\
\text { medo de decepcionar; na escola } \\
\text { também se cobra muito, tudo tem } \\
\text { que estar perfeito. }\end{array}$ \\
\hline Q3 & 15 meses & $\begin{array}{l}\text { Muito mais confiante, enfrenta as } \\
\text { situações; } \\
\text { Mais alegre; } \\
\text { Conversa mais sobre seus medos } \\
\text { e preocupações; } \\
\text { Impõe mais suas vontades. }\end{array}$ \\
\hline
\end{tabular}

Nota: Q1 = Questionário 1, Q2 = Questionário 2 e assim por diante.

Para Luyten et al. (2012), há uma similaridade importante entre o processo terapêutico e o processo normal de desenvolvimento. Esse paralelismo tem uma implicação significativa, pois, já que muitos processos de desenvolvimento psicológico não são lineares, não há razão para supor que o processo de mudança na psicoterapia será linear.

No caso de Walter, houve uma mudança de escola, que favoreceu melhoras, na visão de sua mãe. Houve também a separação dos pais. Nos casos de Pedro e Alice, familiares de ambos adoeceram gravemente, e Antônio vivia num entorno familiar com alto nível de conflito. Portanto, o contexto das crianças deve ser considerado (Kernberg et al., 2012).

As mudanças identificadas pelos pais e mães participantes deste estudo foram relacionadas aos três grupos descritos por Strupp (2013): desaparecimento dos sintomas, melhora no funcionamento mental e ajustamento à realidade. No caso de Walter, grande parte das mudanças percebidas pela mãe foram relacionadas à melhora ou piora nos sintomas (diminuição das alterações abruptas de temperamento, menor agressividade, maior entrosamento na escola e, por outro lado, regressões e dificuldades para completar tarefas escolares), e à superação de comportamentos regressivos (abrir mão da mamadeira aos seis meses de psicoterapia, maior autonomia em seus cuidados pessoais aos 12 meses). Na visão de seu pai, aos seis meses de psicoterapia, Walter estava mais concentrado nas tarefas escolares e mais entrosado com seus colegas. Aos 12 e 20 meses, tais mudanças foram mantidas, sendo observada também menor impulsividade e reatividade.

Para além da melhora sintomática, os pais de Walter identificaram mudanças em seu funcionamento mental. De acordo com ambos, aos seis meses de psicoterapia, Walter demonstrava maior autoconfiança; aos 12 meses, mais segurança, segundo a mãe; investimentos mais positivos, como o desejo de obter bom rendimento e ser aprovado para o ano seguinte, aos 25 meses, conforme o pai. Aos 32 meses, Walter era uma criança menos ansiosa (Q5, mãe), investia mais na escola (Q5, pai), demonstrava mais empatia (Q5, mãe), e parecia caminhar no sentido de uma autoimagem mais positiva (Q5, pai). No final da psicoterapia, Walter era uma criança mais segura, que conseguia expressar seus sentimentos e pensamentos (Q7, mãe), e mais independente (Q7, pai). Tais mudanças também foram enfatizadas por Copollillo (1990), Kernberg et al. (2012) e Sandler (1982) ao considerar a evolução do processo terapêutico de crianças. 
Algumas mudanças descritas pelos pais de Walter foram consideradas na categoria do ajustamento à realidade, especialmente no que diz respeito à melhora na qualidade dos seus relacionamentos interpessoais (Strupp, 2013). Embora a dificuldade de relacionamento com os pares fosse um dos seus sintomas antes da psicoterapia, superada essa dificuldade, aos 20 meses (Q3, mãe e pai), o seu relacionamento com colegas continuou melhorando e foi assinalado como uma das mudanças mais marcantes nos meses seguintes, tanto pelo pai como pela mãe (Q4, Q5, Q6 e Q7).

No caso de Pedro, mudanças na categoria dos sintomas relacionados à escola foram percebidas pela mãe somente a partir dos 15 meses de psicoterapia (Q4, Q5, Q6, Q8 e Q9). Para o pai, Pedro já apresentava melhor desempenho em suas atividades escolares aos quatro meses de psicoterapia (Q1). Essa evolução continuou de maneira significativa aos 15 meses (Q4), e foi novamente observada aos 22 e aos 30 meses (Q5 e Q7) e no final do tratamento, aos 43 meses (Q9), com a ressalva de alguns problemas de atenção aos 30 meses (Q7).

Para a mãe de Pedro, as mudanças em seu funcionamento mental tiveram maior destaque em várias etapas da psicoterapia (Copollillo, 1990; Kernberg et al., 2012; Strupp, 2013). Melhora na ansiedade de separação, flexibilização em padrões rígidos e repetitivos de conduta e capacidade de expressar os sentimentos foram assinaladas aos quatro e sete meses (Q1 e Q2). A capacidade de identificar e expressar sentimentos voltou a ser assinalada aos 22 e 26 meses (Q5 e Q6), assim como no final da psicoterapia (Q9). Pedro ampliou seu leque de interesses e capacidade de sublimação, conforme a mãe, começando a praticar atividade esportiva depois de 36 meses (Q8). No final da psicoterapia, era um menino mais maduro, autoconfiante, seguro, autônomo, feliz e menos angustiado (Q9). Considerando-se que fora diagnosticado com Transtorno de Asperger, trata-se de mu- danças que podem ser consideradas clinicamente significativas.

De acordo com o pai de Pedro, mudanças no seu funcionamento mental também foram reportadas. Aos quatro e aos sete meses de psicoterapia, tais mudanças diziam respeito, principalmente, a uma maior capacidade de expressar suas emoções, maior autoestima e a posicionar-se de forma mais autônoma (Q1 e Q2). Depois de 22 meses, sentia o filho mais feliz e mais espontâneo, e novamente destacou sua melhora para demonstrar seus sentimentos (Q5). Aos 30, 36 e 43 meses, o pai de Pedro salientou sinais relacionados ao início da pré-adolescência, mudanças de interesse, conversas mais maduras e alternância de comportamentos infantis e adolescentes (Q7, Q8 e Q9).

Quanto à categoria de ajustamento à realidade, descrita por Strupp (2013), os pais de Pedro destacaram maior capacidade de se posicionar e defender diante dos pares, aos sete meses de tratamento (Q2), e melhor interação com os pares (Q4, mãe). Para o pai, depois de sete meses, Pedro sentia-se mais seguro em relação ao vínculo com ele, depois da separação do casal (Q2). Também destacou maior proximidade com o filho, aos 15 meses (Q4).

$\mathrm{Na}$ mesma época em que o pai reportou mudanças relacionadas ao início da adolescência (Q7, Q8 e Q9), a mãe destacou que Pedro estava mais rebelde, mais agressivo, teimoso e "respondão". É possível que, pelo tipo de vínculo estabelecido entre mãe e filho, entre pai e filho, e também pela maior convivência diária do menino com a mãe, com quem morava, o mesmo comportamento tenha sido descrito de maneira diferente por pai e mãe -como uma evolução, no primeiro caso, e como uma regressão, no segundo.

No caso de Alice, as mudanças percebidas por sua mãe se concentraram na categoria dos sintomas e da melhora do funcionamento mental (Copolli1lo, 1990; Kernberg et al., 2012; Sandler, 1982; Strupp, 2013). Após os três primeiros meses de 
psicoterapia, os sintomas que a trouxeram para tratamento haviam sido superados: cessaram as queixas somáticas e houve melhora na sua adaptação à escola (Q1).

Entretanto, ao responder o questionário no oitavo mês de psicoterapia, a mãe de Alice relatou uma piora, depois de melhora em relação às dores e cabeça e à escola. As dores voltaram, surgiu novo sintoma somático (coceiras no corpo), traços obsessivos e ansiedade de separação (Q2). Nesse período, a avó de Alice teve um grave problema de saúde. Entre os três e os oito meses de tratamento, também ocorreu a gravidez da terapeuta. Além disso, deve-se lembrar que a menina atravessava um período de luto pela perda do pai.

Contudo, Alice era uma criança que apresentava importantes recursos psíquicos, capacidade reflexiva, e se engajou no tratamento de maneira significativa. Estabeleceu uma sólida aliança terapêutica desde o início, e possibilitava o trabalho baseado na interpretação e análise da transferência de forma a examinar seus conflitos e experiências traumáticas.

Em seu último questionário (Q3), a mãe de Alice relatou mudanças na categoria das melhoras no funcionamento mental descrita por Strupp (2013), Kernberg et al. (2012) e Copollillo (1990). Depois de 15 meses, Alice se mostrava mais confiante, segura, alegre e mais capaz de identificar e falar sobre suas emoções, sentimentos e desejos.

No caso de Antônio, de maneira geral, não foram relatadas mudanças significativas nos questionários de seus pais. Dos cinco questionários, seu pai respondeu a apenas dois, limitando-se a colocar que "nada mudou". Da perspectiva da sua mãe, aos quatro, sete e 15 meses, Antônio continuava agressivo, irritado e descontrolado (Q1, Q2 e Q4). Um fator que pode ter contribuído para essa divergência nas percepções dos pais é a postura distante do pai na família e na psicoterapia do menino, além dos conflitos conjugais, relatados acima.

Aos 11 meses, por outro lado, sua mãe observou melhora em seu funcionamento mental, com uma diminuição da ansiedade e agressividade, e melhora na capacidade de organização (Q3). Ao mesmo tempo, foi referida uma mudança no sentido do ajustamento à realidade (Copollillo, 1990; Kernberg et al., 2012; Strupp, 2013), com uma melhora no relacionamento interpessoal (com a mãe), que se manteve aos 15 meses em relação aos amigos (Q4) e aos 22 meses em relação à mãe (Q5). Nesses dois períodos, a mãe de Antônio observou mudança em seu funcionamento mental, em termos de maior autonomia, amadurecimento e entrada na adolescência (Q4 e Q5).

O caso de Antônio, assim como os outros três casos participantes deste estudo, vai ao encontro do que Luyten et al. (2012) assinalaram: de que o processo de mudança na PP não é linear. Da mesma forma, foi possível observar que cada paciente evidenciou uma trajetória de mudança e crescimento única, como foi assinalado por esses autores.

A não linearidade das mudanças na psicoterapia psicodinâmica foi também corroborada pelo fato de que, em cada caso, as mães relataram mudanças com relação a uma das categorias consideradas (por exemplo, melhora no funcionamento mental ou ajustamento à realidade), porém piora em relação a alguma outra categoria (nos sintomas, por exemplo). Isso aconteceu no caso Walter em Q2, Q5 e Q6, no caso de Pedro em Q2, Q4, no caso de Alice, em Q2 e no caso de Antônio, em Q1 e Q4. Curiosamente, nas respostas dos pais, as mudanças relatadas foram sempre no sentido das melhoras, não sendo assinalados os elementos contraditórios observados pelas mães. Uma hipótese para esse achado é que, de maneira geral, as mães se ocupavam mais dos cuidados e do dia a dia das crianças e, por isso, deparavam-se com maior frequência com as suas dificuldades, sendo também mais sensíveis às mesmas. Outra hipótese é que os pais tendiam a valorizar mais os aspectos positivos e saudáveis das crianças, e/ou também a negar mais seus problemas.

Outra diferença observada nas mudanças relatadas pelas mães e pais de três crianças foi que 
mudanças nos comportamentos regressivos (deixar mamadeira, cuidados pessoais, superação de ansiedade de separação) foram reportadas pelas mães, enquanto os pais valorizaram mudanças no âmbito extrafamiliar (escola, relacionamento com amigos, desempenho nos esportes) e relacionadas ao crescimento, entrada na puberdade. É possível que essa diferença resulte do tipo de relação e de cuidados estabelecidos entre a mãe e o filho ou filha, e entre o pai e a criança, além de poder refletir também aspectos de desajustamento na relação do casal parental. Tais resultados também podem ser considerados à luz do lugar que a criança e seus sintomas ocupam na economia psíquica da mãe e do pai, conforme foi assinalado por Faria (2016) e Rosenberg (2002).

Foi possível constatar que as observações dos pais e mães não se limitaram à melhora sintomática. As mudanças no funcionamento mental das crianças descritas acima envolveram melhora nos sentimentos de segurança e autoconfiança, autoimagem mais integrada e positiva, maior diferenciação entre o eu e os outros. Tais mudanças foram descritas por Luyten et al. (2012), e pode-se supor que subjacente a elas, houve mudanças nos estados da mente com relação às experiências de apego, representações do self e dos outros mais diferenciadas e maior integração da identidade, especialmente nos casos de Walter e Pedro, que tiveram tratamentos mais longos.

Uma maior capacidade reflexiva em relação aos próprios estados mentais, assinalada na literatura como uma mudança importante da PP (Kernberg et al., 2012; Luyten et al., 2012), foi descrita pelos pais e mães. Nos casos de Walter, Pedro e Alice, uma mudança descrita várias vezes dizia respeito à capacidade que essas crianças passaram a demonstrar de expressar seus sentimentos, pensamentos, desejos.

A retomada do curso do desenvolvimento e a adaptação das crianças em casa e na escola, também foram mudanças valorizadas em todos os casos, mesmo quando ausentes, como na visão dos pais de Antônio. Nesse sentido, os resultados deste estudo também vão ao encontro da literatura, que descreveu esses elementos como resultados esperados na psicoterapia de crianças (Coppolillo, 1990; Odhammar \& Calberg, 2015; Sandler, 1982).

Em síntese, os resultados deste estudo confirmaram as hipóteses formuladas. Foi possível para dois dos pais e para as mães identificar mudanças no decorrer da psicoterapia de seus filhos, elas não foram lineares e não se restringiram à categoria da melhora sintomática.

Assim, a partir dos resultados, é possível afirmar que a PP foi efetiva em três dos quatro casos discutidos (casos de Walter, Pedro e Alice), de acordo com a visão dos pais das crianças atendidas. No caso de Antônio, desfecho considerado não efetivo, diferentes fatores podem ter contribuído para esse resultado. Tratava-se de uma família vulnerável em alguns aspectos, havia a necessidade de atender o irmão menor que apresentava um transtorno do espectro autista, havia o não envolvimento do pai na vida do filho e na sua psicoterapia. Mesmo assim, a família investiu na psicoterapia do menino por quase dois anos. Fatores ou dificuldades da terapeuta (como, por exemplo, aspectos contra-transferenciais e/ou o fato de estar no início da sua experiência clínica) também devem ser considerados para a compreensão do desenrolar desse processo terapêutico, e outras informações e análises seriam necessárias para sua elucidação.

Foi possível constatar a importância da participação dos pais na psicoterapia das crianças deste estudo, e a importância da escuta e acompanhamento da sua visão acerca do processo terapêutico. Eles podem fornecer importantes feedbacks que contribuem para o andamento e o progresso do tratamento. Quando não participam de modo favorável para essa evolução, como pode ter acontecido no caso de Antônio, sua inclusão também é fundamental, para que suas resistências, dificuldades e defesas possam ser trabalhadas de forma a não dificultar ou impedir o tratamento da criança. 


\section{Referências}

Águila, D., Lama, X., Capella, C., Rodriguez, L., Dussert, D., Gutierrez, C., \& Beiza, G. (2016). Narratives from therapists regarding the process of therapeutic change in children and adolescents who have been victims of sexual abuse. Studies in Psychology, 37(2-3). Doi: doi.org/ 10.1080/02109395.2016.1204780

American Psychiatric Association, APA. (2014). Manual diagnóstico e estatístico de transtornos mentais. DSM-5. Porto Alegre: Artmed.

Carlberg, G. (2009). Exploring change processes in psychodynamic child psychotherapy: The terapist's perspective. En N. Midgley, J. Anderson, E. Grainger, T. Vuckovic-Nesic, \& C. Urwin (Eds.), Child psychotherapy and research: new approaches, emerging findings (pp. 100-112). Nova York, NY: Routledge.

Calberg, G., Thorén, A., Billstrom, S., \& Odhammar, F. (2009). Children's expectations and experiences of psychodynamic child psychotherapy. Journal of Child Psychotherapy, 35(2), 175193. Doi: doi.org/10.1080/00754170902996130 Capella, C., Rodriguez, L., Águila, D., Dussert, D., Lam, X., Gutierrez, C., \& Beiza, G. (2015). Storied images of psychotherapeutic change: approaching children's voices through drawings. Research in Psychotherapy: Psychopathology, Process and Outcome, 18(2), 141-151. Doi: doi.org/10.4081/ripppo.2015.188

Coppolillo, H. (1990). Psicoterapia psicodinâmica de crianças. Porto Alegre: Artes Médicas.

Deakin, E. K., \& Nunes, M. L. T. (2009). Effectiveness of child psychoanalytic psychotherapy in a clinical outpatient setting. Journal of Child Psychotherapy, 35(3), 290-301. Doi: doi. org/10.1080/00754170903244621

Eresund, P. (2007). Psychodynamic psychotherapy for children with disruptive disorders. Journal of Child Psychotherapy. 33(2), 161-180. Doi: doi.org/10.1080/00754170701431347
Faria, M. R. (2016). Introdução à psicanálise de crianças. O lugar dos pais. São Paulo: Toro Editora.

Guimarães, L. P. M., \& Yoshida, E. M. P. (2014). Criteria of progress in children psychotherapies according to psychotherapists. Paidéia (Ribeirão Preto). 24(57), 95-104. Doi: 10.1590/198243272457201412

Heede, T., Runge, H., Storebo, O. J., Rowley, E., \& Hansen, K. G. (2009). "Psychodynamic milieu-therapy and changes in personality - what is the connection?' Journal of Child Psychotherapy, 35(3), 276-289. Doi: doi. org/10.1080/0075417090323728

Kernberg, P.F., Ritvo, R., Keable, H., \& The American Academy of Child and Adolescent Psychiatry (AACAP) Committee on Quality Issues (CQI). (2012). Practice parameter for psychodynamic psychotherapy with children. Journal of the American Academy of Child \& Adolescent Psychiatry, 51(5), 541-557. Doi: 10.1016/j. jaac.2012.02.015

Luyten, P., Blatt, S. J., \& Mayes, L. C. (2012). Process and outcome in psychoanalytic psychotherapy research: the need for a (relatively) new paradigm. En R. A. Levy, J. S. Ablon, \& H. Kächele (Eds.), Psychodynamic psychotherapy research: evidence-based practice and practice-based evidence (pp. 345-359). New York: Humana Press.

Midgley, N., \& Kennedy, E. (2011). Psychodynamic psychotherapy for children and adolescents: a critical review of the evidence base. Journal of Child Psychotherapy. 37(3), 232-260. Doi: doi. org/10.1080/0075417X.2011.614738

Odhammar, F., \& Calberg, G. (2015). Parents' and psychotherapists' goals prior to psychodynamic child psychotherapy. European Journal of Psychotherapy \& Counseling, 17(3). Doi: 10.1080/13642537.2015.1059865

Odhammar, F., Sundin, E. C., Jonson, M., \& Calberg, G. (2011). Children in psychodynamic psychotherapy: changes in global functioning. 
Journal of Child Psychotherapy, 37(3), 261-279. Doi: doi.org/10.1080/0075417X.2011.614744

Oliveira, L. R., Gastaud, M., \& Ramires, V. R. R. (2016). Parent participation in child psychoanalytic psychotherapy. Revista Brasileira de Psicoterapia, 18(2), 74-91. Recuperado de http://rbp.celg.org.br/detalhe_artigo.as$\mathrm{p}$ ? id $=203$

Palmer, R., Nascimento, L. N., \& Fonagy, P. (2013). The state of the evidence base for psychodynamic psychotherapy for children and adolescents. Child and Adolescent Psychiatric Clinics of North America, 22, 149-214. Doi: doi. org/10.1016/j.chc.2012.12.001

Rosenberg, A. M. S. (2002). A constituição do sujeito e o lugar dos pais na análise de crianças. En: A. M. S. Rosenberg (org.). O lugar dos pais na psicanálise de crianças (pp. 45-78). São Paulo: Escuta.

Sandler, J. (1982). Técnica da Psicanálise Infantil. Porto Alegre: Artes Médicas.

Strupp, H. (2013). The outcome problem in psychotherapy revisited. Psychotherapy, 50(1), 3-11. Doi: doi.org/10.1037/h0094491

\section{Recebido: 04 de março de 2017} Aprovado: 04 de junho de 2018
Target, M., March, J., Ensink, K., Fabricius, J., \& Fonagy, P. (2002). Prospective study of the outcome of child psychoanalysis and psychotherapy (AFC). En P. Fonagy (Ed.), An Open Door Review of Outcomes Studies in Psychoanalysis. London: International Psychoanalytic Association.

Trowell, J. et al. (2007). Childhood depression: a place for psychotherapy. An outcome study comparing individual psychodynamic psychotherapy and familiy therapy. European Child and Adolescent Psychiatry, 16(3), 157-167. Doi: doi.org/10.1007/s00787-006-0584-x

Verheugt-Pleiter, A. J. E., Zevalnkink, J., \& Schmeets, M. G. J. (2008). Mentalizing in child therapy. Guidelines for clinical practioners. London: Karnac.

Weiz, J. R., Doss, A. J., \& Hawley, K. M. (2005). Youth psychotherapy outcome research: a review and critique of the evidence base. Annual Review of Psychology, 56, 337-363. Doi: doi. org/10.1146/annurev.psych.55.090902.141449 